\title{
Levantamento da situação do processo de licenciamento ambiental do setor saúde em Belo Horizonte - MG, Brasil
}

\author{
Ilka S. Cintra \\ ilkasc@ufmg.br \\ Renata T. Miari \\ renata.miari@tmengenharia.com
}

\section{RESUMO}

O Licenciamento Ambiental de estabelecimentos de saúde, particularmente de hospitais em Belo Horizonte Minas Gerais vem sendo discutidos desde 2002, com a tentativa de adequações, quando do estabelecimento das novas legislações da Agencia Nacional de Vigilância Sanitária -ANVISA (2004) e Conselho Nacional de Meio Ambiente -CONAMA (2005), pertinentes ao setor. Neste sentido, o presente trabalho objetivou analisar a situação do Licenciamento Ambiental do setor saúde na cidade de Belo Horizonte em Minas Gerais no Brasil e verificar se o estudo das dificuldades apontadas no licenciamento dos hospitais de Belo Horizonte poderia representar um avanço para a sustentabilidade ambiental do município. Os resultados obtidos puderam respaldar importantes alterações na Diretriz Normativa relativa ao Licenciamento Ambiental do Município de Belo Horizonte, além de modificação nos Termos de Referência para Elaboração de Projetos Técnicos necessários para obtenção das licenças ambientais nos diferentes órgãos responsáveis pelo Licenciamento Ambiental e que se tornaram referência para o Estado de Minas Gerais.

PALAVRAS-CHAVE: resíduos de serviços de saúde; licenciamento ambiental; hospitais; sustentabilidade ambiental.

\section{INTRODUÇÃO}

Acredita-se que a sustentabilidade ambiental de um município pode ser afetada pela regularização ambiental dos empreendimentos do setor saúde desta localidade, principalmente no que tange ao correto manejo dos resíduos de serviços de saúde produzidos em seus hospitais.

O licenciamento de estabelecimentos de saúde, particularmente de hospitais em Belo Horizonte -Minas Gerais vem sendo discutidos desde 2002, com a tentativa de adequações, quando do estabelecimento das novas legislações da Agencia Nacional de Vigilância Sanitária -ANVISA (2004) e Conselho Nacional de Meio Ambiente -CONAMA (2005), pertinentes ao setor. Em Belo Horizonte o procedimento inicia-se com o requerimento da guia de Orientação ao Licenciamento Ambiental - OLA que aponta a listagem da documentação necessária que o empreendedor do setor saúde deve apresentar, destacando-se a aprovação do Plano de Gerenciamento de Resíduos de Serviços de Saúde - PGRSS nas instâncias competentes. Neste sentido, o presente trabalho objetivou analisar a situação do Licenciamento Ambiental do setor saúde em Belo Horizonte, Minas Gerais e verificar se o estudo das dificuldades apontadas no licenciamento dos hospitais de Belo Horizonte poderia representar um avanço para a sustentabilidade ambiental do município.

O trabalho foi elaborado em atendimento à solicitação do Ministério Público do Estado de Minas Gerais - MPE-MG que apontava morosidade nos licenciamentos dos hospitais. Tornava-se urgente averiguar se a responsabilidade era apenas dos empreendedores do setor saúde ou dependia, também do sistema de Licenciamento Ambiental do município. O MPE-MG para encaminhamento da situação realizou reunião (em 23/10/2006 na sede da Procuradoria-Geral de Justiça) com representantes dos estabelecimentos de saúde de Belo Horizonte, órgãos públicos notificados e a Promotora de Justiça à época. A pauta se referiu ao Licenciamento Ambiental e Plano de Gerenciamento de Resíduos Sólidos de Saúde -PGRSS, a ser implantado por todas as unidades de saúde de Belo Horizonte até 31/12/06, em atendimento 
ao Decreto $\mathrm{PBH} \mathrm{n}^{\circ}$ 12.165/05 da Prefeitura Municipal de Belo Horizonte. Como resultados da reunião ficaram estabelecidos:

- implantação do PGRSS até 30 de abril de 2007 e,

- apresentação, no prazo de 15 dias, de um relatório das dificuldades de cada hospital com relação ao cumprimento dos requisitos da OLA devendo, inclusive, ser arcada reunião com a Secretaria Municipal Adjunta de Meio Ambiente -SMAMA, a fim de que a relação da conjugação dos prazos da OLA e Termo de Ajustamento de Conduta -TAC's seja enviada ao MPE-MG, com as respectivas justificativas

A Associação de Hospitais de Minas Gerais - AHMG através de sua Comissão Técnica de Meio Ambiente - COTEMA deu atendimento a esta solicitação do Ministério Público de Belo Horizonte.

Assim, o trabalho intitulado Relatório da Situação dos Hospitais de Belo Horizonte-Processo de Licenciamento Ambiental (Cintra, 2006) foi desenvolvido a partir da análise dos questionários construídos pela equipe da COTEMA, respaldado nas informações fornecidas pelos órgãos ligados ao licenciamento em Belo Horizonte, e distribuídos aos Hospitais associados da AHMG. Entregue ao MPE em 27/12/07 foi o trabalho avaliado e requeridas outras informações complementares que compuseram o Relatório da Situação dos Hospitais de Belo Horizonte - Processo de Licenciamento Ambiental - $2^{\mathrm{a}}$ Etapa (Cintra, 2007a).

Como os dois relatórios constituem-se em volumes apreciáveis foi solicitado pelo Excelentíssimo Prefeito do Município de Belo Horizonte, Dr. Fernando da Mata Pimentel um resumo do conteúdo dos trabalhos desenvolvidos e denominados de Síntese do Levantamento da Situação do processo de Licenciamento Ambiental do Setor Saúde em Belo Horizonte - MG (Cintra, 2007b).

Particularmente, ficou evidenciada a situação dos hospitais frente às dificuldades de aprovação dos Plano de Gerenciamento de Resíduos de Serviços de Saúde dos estabelecimentos de saúde no município -PGRSS face aos Pareceres da Secretaria Municipal de Saúde - SMSA e da Superintendência de Limpeza Pública -SLU.

Finalmente, como resultados obtidos com o trabalho obteve-se importantes alterações na Diretriz Normativa relativa ao Licenciamento Ambiental do Município de Belo Horizonte, além de modificação nos Termos de Referência para Elaboração de Projetos Técnicos necessários para obtenção das licenças ambientais nos diferentes órgãos responsáveis pelo Licenciamento Ambiental e que se tornaram referência para o Estado de Minas Gerais.

\section{MATERIAIS E MÉTODOS}

A metodologia de trabalho consistiu, primeiramente, na busca de diálogos com as instituições envolvidas no licenciamento ambiental do município de Belo Horizonte para discussões, adequação e apontamento daqueles requisitos realmente pertinentes ao setor e importantes para efetivação das licenças para os hospitais do município. Concomitantemente, também foram construídos formulários-base sobre a documentação requerida por cada uma destas instituições em relação ao licenciamento ambiental e respondidos pelos hospitais para avaliação individual do caminho de cada hospital e para determinação das maiores dificuldades do setor.

Construído o formulário com a pretensão primeira de um panorama das questões relativas ao licenciamento ambiental do município, junto aos diversos órgãos envolvidos no processo, o mesmo foi, então, distribuído aos 50 hospitais associados à Associação dos Hospitais de Minas Gerais - AHMG. Deste universo, 37 (trinta e sete) apresentaram o formulário e 30 (trinta) tiveram suas respostas compiladas e analisadas (pois 4 destes hospitais já posuíam o Licenciamanto Ambiental finalizado e 3 ou não foram chamados ou foram liberados do processo de licenciamento ambiental. As respostas obtidas a partir dos formulários-base enviados aos hospitais particulares de Belo Horizonte foram analisadas e a tabulação dos dados produziu informações suficientes para um adequado reconhecimento da situação atual do licenciamento dos hospitais de Belo horizonte.

\section{RESULTADOS OBTIDOS}

Os resultados obtidos a partir da análise das respostas dos 30 (trinta) formulários-base foram primeiramente analisados isoladamente e posteriormente relacionados entre si.

Considerando as respostas apresentadas pelos estabelecimentos de saúde em relação ao Parecer da Secretaria Municipal Adjunta de Regulação Urbana -SMARU, pode-se perceber que a idade média das edificações onde se estabelecem os hospitais é de 41 anos e que apenas $20 \%$ dos hospitais não iniciaram 
o processo para obtenção do Parecer sobre a conformidade legal do empreendimento frente à legislação urbanística. Especificamente em relação à questão "Existe outro problema quanto à regularização do imóvel junto a SMARU?" e em relação de documentos faltantes para a conclusão do processo junto a SMARU tem-se que as maiores dificuldades se constituíram em:

- Regularização da edificação frente a acréscimos ocorridos.

- Altos custos.

- Parcelamento do terreno.

- Tombamento da edificação.

- Situação de imóvel alugado

- Morosidade do órgão na análise da documentação.

- Divergência de prazos e pré-requisitos estabelecidos pelos diversos órgãos.

- Documentação do empreendimento e proprietário (baixa de construção, habite-se, usucapião).

Assim, a regularização da edificação frente a acréscimos ocorridos apresentou-se como a maior dificuldade frente a SMARU.

Quanto aos resultados sobre o Parecer da Superintendência de Desenvolvimento da Capital -SUDECAP podese concluir que $30 \%$ dos hospitais não possuem encaminhamento de processo na SUDECAP. Também se percebeu que $42 \%$ do universo dos hospitais possuem área permeável, $62 \%$ apresentam projetos de redes e $88 \%$ possuem rede pública de captação de água pluvial.

Especificamente em relação às respostas apresentadas à pergunta "Existe outro problema quanto ao processo junto a SUDECAP e" Relacione os documentos que faltam para a conclusão do processo junto a SUDECAP "pode-se perceber que as maiores dificuldades se constituíram em":

- Cadastramento de redes.

- Morosidade de análise.

- Custos.

- Cadastramento de drenagem.

- Ligação com a Rede pública.

- Obras da PBH.

- Dependência de dados e documentação de outros órgãos.

- Divergência de prazos e pré-requisitos entre os órgãos.

Com relação à situação do processo de licenciamento frente a BHTRANS obteve-se que 30\% dos estabelecimentos não iniciaram seus processos, $33 \%$ estão com as solicitações em análise e $37 \%$ se encontram com o processo concluído.

E ainda, a partir das respostas constantes do item sobre a BHTRANS pode-se concluir que as maiores dificuldades se constituem em:

- Área de estacionamento.

- Divergência de prazos e prérequisitos entre os órgãos.

- Questionamento das responsabilidades de elaboração de estudos viários no entorno do empreendimento.

- Falta de normalização de procedimentos.

- Morosidade de atendimento de tramitação de documentação.

- $\quad$ Custo.

Cabe ressaltar que o item Área de estacionamento foi citado por $60 \%$ dos hospitais que compõem o universo dos

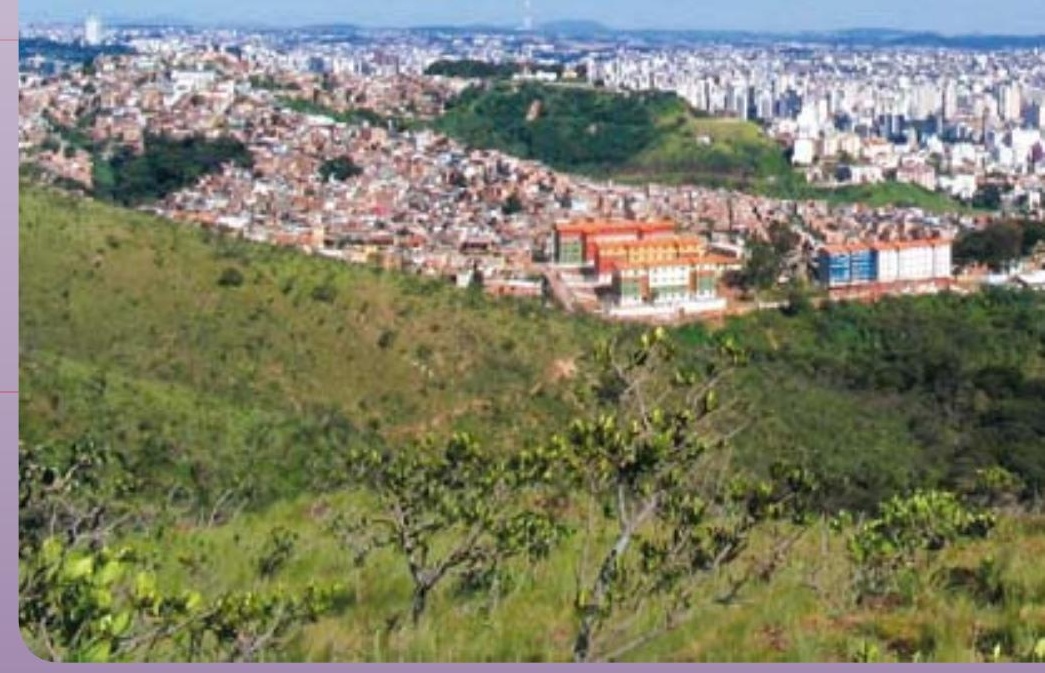


Outros problemas e dificuldades encontradas para a elaboração do RCA e PCA foram apontados como:

- Impossibilidade de protocolizar o RCA e PCA em função da necessidade de aprovação dos pareceres em outros órgãos.

- Levantamento da documentação do estabelecimento.

- Elaboração das pesquisas de opinião.

Finalmente, numa análise do campo de complementação do formulário foram também reforçadas algumas dificuldades colocadas pelo setor, a saber:

- Exigibilidade em atender as novas regras sem flexibilidade, principalmente, por se tratar de instituições antigas.

- Informar dados que não são considerados pelo empreendedor, como de sua competência, a exemplo da BHTRANS que solicita informações sobre o entorno do empreendimento, como vias de acesso, comércio, tamanho do quarteirão. Acredita-se que estes dados sejam de exclusiva responsabilidade destes órgãos e nãoda instituição informar.

- Necessidade de conciliar os quesitos de segurança e pânico com as normas de Patrimônio Histórico.

- A Prefeitura deveria ter apenas uma "Porta de Entrada" para todo o processo de Licenciamento Ambiental de forma a conciliar os prazos internos intra-secretarias e minimizar a burocracia.

Numa análise conjunta de todos os itens contidos no levantamento da situação ambiental do setor saúde fica evidente a dificuldade apontada pela maioria dos empreendedores da área da saúde, a saber, a falta de interação entre os órgãos envolvidos no Licenciamento Ambiental do município. Assim deve-se atentar para uma padronização de procedimentos para a realização das análises da documentação pertinente ao licenciamento ambiental de estabelecimentos de saúde no município de Belo Horizonte, hoje considerado como referência no Brasil.

Outro ponto de interesse da pesquisa, a partir dos resultados obtidos nas diversas reuniões com as instituições envolvidas no licenciamento ambiental do município de Belo Horizonte constituiu nos passos metodológicos propostos pelos órgãos oficiais especificamente para a tipologia hospitalar. A COPASA, num trabalho conjunto com os técnicos da COTEMA/AHMG, elaborou um novo Termo de Referência específico para o desenvolvimento do Projeto Técnico do Programa de Recebimento e Controle dos Efluentes Não Domésticos - PRECEND. Este trabalho resultou em uma simplificação do Termo de Referência anteriormente distribuído pela COPASA permitindo aos hospitais maior agilidade e facilidade na reunião e formatação das informações solicitadas. Foi esclarecido que os hospitais que já haviam iniciado seus trabalhos conforme Termo de Referência antigo poderiam optar por continuarem a apresentar suas informações nesse termo ou poderiam trocar pelo Termo de Referência (de setembro/2007) revisado e em vigor, se assim o desejarem. Entretanto, caso o hospital opte por um determinado Termo de Referência, este deverá ser seguido na íntegra, não sendo aceitas conjugações entre estes dois termos. A SMAMA, após diversas reuniões com os técnicos da COTEMA emitiu um Termo de Compromisso para Autorização Temporária, conforme disposto no capítulo iii, artigo 10 da Deliberação Normativa n. ${ }^{\circ} 42$ de 18 de setembro de 2002, a ser firmado pelo hospital interessado perante o Conselho Municipal do Meio Ambiente -COMAM.

\section{CONCLUSÕES}

Os procedimentos metodológicos adotados no presente trabalho mostraram-se exeqüíveis nas etapas de obtenção e preparação das respostas constituindo-se em importante contribuição, atestada pelos próprios gestores ambientais para a área do licenciamento do setor saúde. A tabulação dos dados produziu informações suficientes para um adequado reconhecimento da situação atual do licenciamento dos hospitais particulares de Belo Horizonte. Assim, ainda que se faça necessária uma maior investigação acerca de sua aplicabilidade, as premissas e metodologias adotadas mostraram-se válidas e adequadas para estudos semelhantes. Convém ressaltar que o trabalho com os demais órgãos responsáveis pela emissão de laudos e pareceres relativos ao Licenciamento Ambiental de estabelecimentos de saúde em Belo Horizonte continuará dentro desta metodologia de negociação e avaliação técnica de todos os envolvidos na questão. Assim através deste estudo pode-se analisar a situação do Licenciamento Ambiental do setor saúde em Belo Horizonte, Minas Gerais e verificou-se que o estudo das dificuldades apontadas no licenciamento dos hospitais de Belo Horizonte pode representar um avanço para a sustentabilidade ambiental do município. 


\section{REFERÊNCIAS BIBLIOGRÁFICAS}

1. Prefeitura Municipal de Belo Horizonte -Decreto Municipal no 12165/2005 de 16/09/05.

2. RESOLUÇÃO ANVISA RDC No 306/2004 de 07/12/04.

3. RESOLUÇÃO CONAMA No 358/2005 de 29/04/05.

4. Cintra I.S.; Cunha R. T. M.; Santos, E. S.; Cunha R.D. Relatório da Situação dos Hospitais de Belo Horizonte - Processo de Licenciamento Ambiental. Associação dos Hospitais de Minas Gerais AHMG. Dezembro de 2006.

5. Cintra I.S.; Cunha R. T. M. Santos, E. S.; Cunha R.D. Relatório da Situação dos Hospitais de Belo Horizonte - Processo de Licenciamento Ambiental - 2a Etapa. Associação dos Hospitais de Minas Gerais AHMG. 2007a.

6 Cintra I.S.;Cunha R. T. M. E. S.; Cunha R.D. Síntese do Levantamento da Situação do processo de Licenciamento Ambiental do Setor Saúde em Belo Horizonte - MG. Associação dos Hospitais de Minas Gerais -AHMG. 2007b. 